\title{
When is Relevance? On the Role of Salience in Utterance Interpretation ${ }^{1}$
}

\author{
Rachel Giora \\ Tel Aviv University
}

\begin{abstract}
Relevance Theory assumes different processing models for similar utterances without motivating the discrepancy (see Giora, 1998). On some occasions (e.g., Sperber and Wilson, 1986/95: 237), it seems to assume a direct access model upon which the contextually appropriate interpretation (e.g., the figurative interpretation of metaphor) is accessed directly without having to process a contextually inappropriate interpretation, (e.g., the literal meaning of metaphor). On other occasions (Sperber and Wilson 1986/95: 242), it seems to assume a special sequential model upon which the contextually inappropriate meaning or structure is involved in deriving the intended meaning. The graded salience hypothesis (Giora, 1997) may help reconcile the inconsistency. According to the graded salience hypothesis, salient (i.e., coded) meanings of words or expressions (whose degree of salience is affected by e.g., frequency, familiarity, conventionality) and salient (e.g., frequent) structures should always be accessed and always tirst, regardless of contextual bias or speaker's intent. According to the graded salience hypothesis, direct process should apply when salient information is intended, i.e., when salient information is compatible with contextual information. Sequential process should be induced when less salient meanings are intended (e.g., the literal meaning of conventional idioms). On such occasions, salient meanings would not be bypassed; Rather, they would be activated first, rejected as the intended meaning and reinterpreted in consistency with the Principle of Relevance. Given the graded salience hypothesis, processes consistent with the Principle of Relevance may apply at different temporal moments of understanding, depending on the salience status of the discourse components involved.
\end{abstract}


The 'standard pragmatic model' (notably Grice, 1975; Searle, 1979) and the Relevance Theoretic account (notably Sperber and Wilson, 1985/96) both assume, among other things, that "the role of pragmatic theory is to explain how the hearer recognises the intended interpretation of an utterance" (Smith and Wilson, 1992: 8). They seem, however, to differ over the role context plays in utterance interpretation. Sperber and Wilson assume that the context (the set of contextual assumptions) "is generally not fixed in advance: it has to be constructed as part of the interpretation process. Sperber and Wilson see this as yet another way in which the interpretation of an utterance in underdetermined by what is linguistically encoded, and argue that context construction is governed by the same general principles that affect the recovery of explicit content and implicatures." (Smith and Wilson, 1992: 3).

As illustration, consider (1) --- a remark once made by Mrs. Thatcher in a radio interview, cited and analyzed by Smith and Wilson (1992: 3):

\section{(1) I always treat other people's money as if it were my own.}

The interpretation of this utterance will be significantly affected by the contextual assumptions brought to bear. On the assumption that Mrs Thatcher treats her own money very carefully, it will implicate that she treats other people's money very carefully; on the assumption that she spends her own money in any way she chooses, it will implicate that she spends other people's money in any way she chooses, and so on.

According to the Relevance Theoretic account cited here, context directs utterance interpretation entirely; The conventional (coded) meaning of Thatcher's utterance (denoting/implying careful treatment of other people's money, regardless of context) is bypassed. Instead, what affects interpretation is the contextual information, i.e., the hearer's contextual assumption(s) about Thatcher's demeanor.

Assigning to context such a role in utterance interpretation is consistent with the direct access view of the lexical processes involved in comprehension (e.g., Simpson, 1981; Glucksberg, Kreuz and Rho, 1986; Jones, 1991). Research into lexical access and ambiguity resolution has shown that context affects interpretation significantly. Heavily biasing contexts inhibit contextually inappropriate meanings so that only the intended meaning is made available for comprehension. Comprehension of ambiguous words embedded in a rich and supportive context did not involve a contextually inappropriate stage. Accessing the intended meaning directly, without recourse to the word's multiple meanings suggests that context pre-selects the contextually appropriate meaning so that only the intended --- contextually compatible --- meaning is made available for comprehension.

Such view must assume equivalent processes for e.g., literal and figurative language. If context affects comprehension completely, comprehenders should compute only the intended, contextually appropriate or optimally relevant meaning, be it literal or figurative, depending on the contextual bias. Interpreting nonliteral language, then, need not involve a contextually inappropriate (e.g., literal) stage at all. It should, therefore, take no longer to process than literal language, and should require no special process (cf. Sperber and Wilson's (1986/95: 239). For the purpose of this discussion, let us focus on irony 
comprehension. As illustration, consider the ironic and literal discourses in 2 and 3, cited and analyzed in Sperber and Wilson's (1986/95: 239):

(2)(a) He: It's a lovely day for a picnic.

[They go for a picnic and the sun shines.]

(2)(b) She: (happily): It's a lovely day for a picnic, indeed.

(3)(a) He: It's a lovely day for a picnic.

[They go for a picnic and it rains.]

(3)(b) She: (sarcastically): It's a lovely day for a picnic, indeed.

In both (2b) and ( $3 b)$ there is an echoic allusion to be picked up. In the circumstances described, it is clear that the speaker of ( $2 b)$ endorses the opinion echoed, whereas the speaker of (3b) rejects it with scorn. These utterances are interpreted on exactly similar patterns; the only difference is in the attitudes they express. (2b) has not been thought of by rhetoricians to be worthy of special attention; ( $3 b$ ) is, of course, a case of irony.

Indeed, empirical evidence obtained for the last two decades seems to have lent support to the direct access account regarding nonliteral language. In all, figurative and literal language have been shown to involve similar processes (see Gibbs, 1994 for a review). Like literal meanings, metaphoric meanings have been shown to be processed automatically (Gildea and Glucksberg, 1983; Glucksberg, Gildea and Bookin, 1982; Keysar, 1989) and to involve the same categorization procedures (Glucksberg and Keysar, 1990; Shen, 1997). Further, metaphors and idioms and their literal interpretation were shown to take equally long to read when embedded in a rich and supportive context (Kemper, 1981; Inhoff, Lima and Carroll, 1984; Ortony, Schallert, Reynolds and Antos, 1978). And irony was no exception: It was found to take no longer to read than its literal equivalent (Gibbs, 1986a,b; Gibbs et al., 1995).

Pragmaticians advocating the direct access view argue against 'the standard pragmatic model' (notably Grice, 1975 and Searle, 1979 and see also e.g., Bredin, 1997 and criticism thereof; Dascal, 1987, 1989). According to Grice and Searle, comprehenders compute the sentence (literal) meaning first, regardless of contextual bias. If it is compatible with the situation or context, it is accepted as the intended meaning and search is stopped. If it is incompatible with the context, it is rejected and replaced by a compatible nonliteral meaning. In this framework, literal meaning enjoys a privileged status - it is always activated and always initially. Interpreting nonliteral language such as metaphor, irony, or indirect requests should, therefore, involve a special sequential process. It should take longer than interpreting literal language which requires no reinterpretation phase.

The standard pragmatic model is consistent with the modular view (cf. Fodor, 1983) which maintains that lexical processes are autonomous: Context does not affect the initial access of a word's coded meanings. Rather, it selects the appropriate meaning after the word's meanings have been retrieved (Gernsbacher, 1990; Keysar, Barr, Balin and Paek in press; Onifer and Swinney, 1981; Rayner, Pacht and Duffy, 1994; Swinney, 1979). 
Findings supporting the modular view regarding irony comprehension include different reading times and different reaction times to literally and ironically related probes. For example, Dews and Winner (1997) and Giora, Fein and Schwartz (1998) found longer reading times for utterances in ironically than in literally biasing contexts (and see also reinterpretation of Gibbs', 1986a findings in Giora, 1995). In addition, Giora et al. (1998) found facilitation for literally related concepts displayed $150 \mathrm{msec}$ after offset of target sentences in ironically and literally biasing contexts. However, at a later stage --- $2000 \mathrm{msec}$ after offset of the target sentence (in the contexts biasing the meaning towards the ironic interpretation) --- the ironic meaning became available and the literal meaning was still as active. Such findings support the view that ironies are initially processed only literally (and see also Giora and Fein, in press a).

Findings supporting the modular view regarding novel metaphor comprehension include different reading times and different reaction times to literally and metaphorically related probes. For example, Giora, Fein and Schwartz (in prep.) found longer reading times for novel metaphors than for their literal interpretations. Blasko and Connine (1993) found that the literal meanings of novel metaphors were facilitated immediately $(0-350 \mathrm{msec}$ after offset of the target sentences), while their metaphoric meanings became available only at a later stage ( $750 \mathrm{msec}$ after offset of the target sentences). Such findings support the view that novel metaphors are processed only literally initially.

Moreover, familiar metaphors which, indeed, took no longer to read than their literal interpretations, were found to access the literal meaning initially, in parallel to their metaphoric meaning, in spite of contextual bias (Blasko and Connine, 1993), and see also Giora and Fein, in press b for converging evidence). Such findings support the view that conventional metaphors are processed metaphorically and literally initially.

How can Relevance theory account for such findings? On the face of it, Relevance theory seems to be consistent with a sequential as well as a direct access model (for similar criticism see also Giora, 1998): Recall that according to Sperber and Wilson (1986/95: 239), irony interpretation requires no special process. However, according to Smith and Wilson (1992), the opposite is true: Here, processing metaphor and irony does involve a special/sequential process:

Let us assume that, in interpreting an utterance, the hearer starts with a small initial context left over, say, from his processing of the previous utterance: he computes the contextual effects of the utterance in that initial context; if these are not enough to make the utterance worth his attention, he expands the context, obtaining further effects, and repeats the processes until he has enough effects to make the utterance optimally relevant in the way that the speaker could manifestly have foreseen. (7, emphasis added)

The interpretation of metaphor and irony involves an element of indirectness. For example, the metaphor 'John is a lion' may communicate indirectly that John is brave. This element of indirectness calls for extra processing effort on the part of the hearer, which ... will be offset by extra effect. (8) 
How can such conflicting views be resolved? Giora (1997, in press) and Giora et al. (1998) proposed a more general view of language comprehension which postulates the priority of salient (rather than literal) meanings (for a similar view see Jurafsky, 1996; Récanati, 1995; Turner and Katz, 1997). A word's salient meanings are those coded in the mental lexicon. Their degree of salience may be affected by e.g., conventionality, familiarity, frequency, or prior context (which is instrumental in enhancing but not in inhibiting coded meanings). According to the graded salience hypothesis (Giora, 1997), salient meanings should always be accessed and always first, regardless of contextual bias. The salience hypothesis, thus, predicts that less familiar, non-salient ironies should be processed literally initially. However, salient, familiar ironies such as wise guy, big deal (whose ironic meaning is coded) should be accessed directly. Giora and Fein (1998) indeed showed that salient ironies facilitated their salient ironic meaning shortly $(150 \mathrm{msec})$ after offset of the ironic target, in parallel to their salient literal meaning. In contrast, non-salient ironies facilitated only their salient literal meaning immediately, i.e., $150 \mathrm{msec}$ after offset of the ironic target; their non-salient ironic meaning was facilitated at a later stage - 1000 msec after offset of the ironic target sentence.

Giora et al. (1998) and Giora and Fein (1998) have also shown that the salient, contextually incompatible (literal) meaning of irony is not suppressed when the ironic meaning emerges. Findings from naturally occurring conversations further support the view that the activated literal meaning of irony is not suppressed, but retained. In studying conversations between friends, Kotthoff $(1998 \mathrm{a}, \mathrm{b})$ has shown that listeners' responses very often resonate with the literal meaning of the immediately preceding ironic utterance while at the same time making it clear that they have also understood the implicated meaning. Findings by Giora and Gur (1998) corroborate Kotthoff's findings, showing that, more often than not, irony is responded to by resonating with its salient literal interpretation.

The graded salience hypothesis indeed posits equivalent activation processes for similarly salient discourses, regardless of whether they are literal or non-literal. ${ }^{2}$ Giora (1997) has shown that the distinction of interest which best explains the various conflicting findings in the field of literal and figurative language understanding is not the metaphoric/literal divide, but rather the salient/non-salient continuum. Under certain circumstances, figurative and literal language behave alike. For instance, less conventional metaphors and conventional idioms used unconventionally behave like highly conventional literal language used innovatively: They were all found to involve a sequential process. On the other hand, conventional metaphors, less conventional idioms, and less conventional literal language used innovatively were found to involved a parallel process. Conventional idioms and conventional literal language, which are instances of conventional language intended conventionally were shown to be accessed directly (cf. Blasko and Connine, 1993; Gerrig, 1989; Gibbs, 1980; McGlone, Glucksberg and Cacciari, 1994).

To account for such conflicting findings in a consistent manner, Relevance Theory will have to incorporate the graded salience assumption. Within this integrated framework, the direct, (presumably context- sensitive) and the autonomous (context-insensitive) processes may occur at different moments of understanding. Context sensitive processes should be 
viewed as monitoring the initial autonomous access phase so that they affect interpretation only after salient meanings/structures have been activated. In the case of e.g., conventional metaphors and ironies, when the figurative meaning is intended, this implies direct access. Since the nonliteral meanings of conventional /familiar metaphors (e.g., 'Richard is a lion') and ironies (e.g. ' wise guy') are salient, they should be accessed initially (and effortlessly; for a different view see Smith and Wilson, 1992: 8). Since they are also the intended meaning, they should not be revised at the monitoring stage, and hence require no special process. ${ }^{3}$ Less familiar and non-familiar language should involve a sequential process upon which the more salient (albeit unintended) meaning should be accessed first, before the nonsalient intended meaning is derived (e.g., less-familiar ironies, novel metaphors, literally intended idioms as evinced by Giora et al., 1998; Blasko and Connine, 1993 and Gibbs, 1980 , respectively).

Similarly, the processes involved in interpreting Thatcher's remark (that she always treats other people's money as if it were her own, cf. Example 1) should involve accessing initially the conventional/salient meaning of the remark (which implicates treatment of other people's money with care). Since this is also her intended meaning, it should not be revised (but selected as the optimally relevant interpretation). However, the addressee entertaining the contextual assumption that she is not careful about money will probably deduce (on his own account) that she is lying, yet he cannot "jump" to this conclusion by bypassing the salient meaning or implication of the remark (as implied by Smith \& Wilson's analysis, see above).

One could argue that lexical access is irrelevant to pragmatics theory. However, given the findings above, a dismissal of lexical processes as irrelevant to utterance interpretation is unwarranted. The sequential process found by Giora et al., 1998 does not imply that a full recovery and rejection of the sentence literal meaning is necessary before computation of the nonliteral meaning begins. What these findings show is that the contextually incompatible (literal) meaning of (irony), which is not inhibited by context, is also not suppressed by the emergence of the intended (ironic) meaning (as would be predicted by Grice and by the proponents of the modular view). Such findings suggest that the contextually incompatible literal meaning may have some role in deriving the ironic interpretation (as proposed by Giora, 1995, Dews and Winner, 1995; Dews, Kaplan and Winner, 1995).

Further, the same processes that were found to be involved in ambiguous and figurative language interpretation have been found to affect anaphora disambiguation. For example, Keysar, Barr, Balin and Paek (in press) show that while searching for anaphor antecedent, the comprehender accesses the most accessible/salient candidate made available by their immediately present context, even though this referent may not be reasonably intended by the speaker. Expansion of the context, at a later stage, avails the alternative, next most accessible candidate, which could also be part of the speaker's and hearer's mutual knowledge, i.e., could be intended by the speaker. As illustration, consider the following example (taken form Keysar et al. in press): 
(4) It is evening, and Boris' young daughter is playing in the other room. Boris, who lives in Chicago, is thinking of calling his lover in Europe. He decides not to call because she is probably asleep given the transatlantic time difference. At that moment his wife returns home and asks, "Is she asleep?"

Keysar et al. (in press) show that retrieving the contextually appropriate referent (i.e., the daughter) is slowed down when there is a more accessible albeit contextually inappropriate candidate (i.e., the lover) than the one that could be intended by the speaker. In Relevance Theory terms, that can be taken to show that the Principle of Relevance (which directs the search for the interpretation that the speaker could manifestly have foreseen) does not affect initial access. Rather, it monitors the comprehension process following the initial access stage. If the most accessible interpretation is consistent with the Principle of Relevance, no revision is required. However, if it is not, it is adjusted and redressed. Horton \& Keysar (1996) further show that such processes are also involved in discourse production. They assume an Initial Design stage which is not amenable to change under time pressure, and a Monitoring and Adjustment stage which is. Indeed, initial plan is shown to involve information that is available to the speaker rather than (mostly) information that might be relevant to the addressee. Tapping information that is consistent with the Principle of Relevance is shown to be induced when the speaker has enough time to monitor and adjust her utterances.

Note that upon the graded salience hypothesis both, the direct access model and the sequential model should involve initial access stage that is autonomous and impervious to context effects. Whereas upon the direct access model, this information is accidentally compatible with contextual information and speaker's intention, upon the sequential model it is not. Though the original direct access model, which is context sensitive, is much more appealing, allowing for context to direct comprehension completely, and consequently spare the comprehender the monitoring and adjustment phase, it is probably not the one guiding our language processing (for a similar view see Keysar, 1994). Keysar, Barr \& Horton (in press) suggest that though "counterintuitive, such error prone processes reflect the information processing limitations of the mind. As Simon $(1956 ; 1982)$ argued, the mind "satisfices": It solves problems heuristically using strategies that are not error proof but are typically cost efficient (Tversky \& Kahneman, 1974)" and often successful, though occasionally erroneous.

Processes consistent with the Principle of Relevance may, then, occur at different temporal phases of the comprehension course. Tapping the optimally relevant interpretation may occur directly, i.e., instantly and effortlessly, e.g., when salient/accessible information is also (accidentally) the intended one - the one consistent with the Principle of Relevance. Or it may require a special (e.g., sequential) effortful processes, e.g., when salient/accessible information is incompatible with contextual information or speaker's intention and has to be revisited. Processes consistent with the Principle of Relevance may apply, then, at different temporal moments of understanding, depending on the salience status of the discourse components involved. 


\section{Notes}

1. This study was supported by The Israel Science Foundation (grant no. 891/96-7). I would also like to thank Boaz Keysar for his very helpful comments.

2. Note, however, that the graded salience hypothesis has no predictions as to the processes of retention or suppression (of the activated meanings/constructions) that are involved in interpreting e.g., ambiguity, metaphor, irony, joke, etc.

3. On the neurological aspects of monitoring see Zaidel (1987).

\section{Works Cited}

Blasko, G.D. and C. Connine. "Effects of familiarity and aptness on metaphor processing." Journal of Experimental Psychology: Learning, Memory, and Cognition, 19(2), (1993): 295-308.

Bredin, H. "The semantic structure of verbal irony." Journal of Literary Semantics XXVI/1 (1997): 1-20.

Dascal, M. "Defending literal meaning." Cognitive Science 11 (1987): 259-281.

. "On the role of context and literal meaning in understanding." Cognitive Science 13 (1989): 253-257.

Dews, Sh., J. Kaplan and E. Winner. "Why not say it directly? The social functions of irony." Discourse Processes 19 (1995): 347-368.

Dews, Sh. and E. Winner. "Muting the meaning: A social function of irony." Metaphor and Symbolic Activity 10 (1995): 3-19.

"Attributing meaning to deliberately false utterances: The case of irony." The Problem of Meaning: Behavioral and Cognitive Perspectives. Eds. Ch. Mandell and A. McCabe Amsterdam: Elsevier, 1997, 377-414.

Fodor, J. The modularity of mind. Cambridge: MIT Press, 1983.

Gernsbacher, M. A. Language Comprehension as Structure Building. Hillsdale N.J.: Erlbaum, 1990.

Gerrig, R.J. "The time course of sense creation." Memory \& Cognition, 17 (1989): 194-207.

Gibbs, R.W. Jr. "Spilling the bean on understanding and memory for idioms in conversation." Memory \& Cognition 8 (1980): 449-456.

. "On the psycholinguistics of sarcasm." Journal of Experimental Psychology:

General 115 (1986a): 3-1.5.

. "Comprehension and memory for nonliteral utterances: The problem of sarcastic indirect requests." Acta Psychologica 62 (1986b): 41-57.

The poetics of mind. Cambridge: Cambridge University Press, 1994.

Gibbs, R.W. Jr., J. E. O'Brien, Sh. Doolittle "Inferring meanings that are not intended: Speakers' intentions and irony comprehension." Discourse Processes 20 (1995): 187-203.

Gildea, P. and S. Glucksberg "On understanding metaphor: The role of context." Journal of Verbal Learning and Verbal Behavior 22 (1983): 577-590.

Giora, R. "On irony and negation." Discourse Processes 19 (1995): 239-264.

"Understanding figurative and literal language: The graded salience hypothesis." Cognitive Linguistics 7/1 (1997): 183-206. 
. "Discourse coherence is an independent notion: A reply to Deirdre Wilson." Journal of Pragmatics 29/1 (1998): 75-86.

"On the priority of salient meanings: Studies of literal and figurative language." Journal of Pragmatics (in press).

Giora, R. and O. Fein. "Irony comprehension: The graded salience hypothesis." Humor (in press a).

"On understanding familiar and less-familiar figurative language." Journal of Pragmatics (in press b).

. "Familiar and less familiar ironies: The graded salience hypothesis." Paper submitted for publication (1998).

Giora, R. O. Fein and T. Schwartz. "Irony: Graded salience and indirect negation." Metaphor and Symbol 13/2 (1998): 83-101.

"On the time course of understanding metaphor." Unpublished ms. Tel Aviv University (in prep.).

Giora, R. and I. Gur. "Irony in conversation: The graded salience hypothesis." Unpublished ms. Tel Aviv University (1998)

Glucksberg, S., P. Gildea and H.G. Bookin. "On understanding nonliteral speech: Can people ignore metaphors?" Journal of Verbal Learning and Verbal Behavior 21(1998): 85-98.

Glucksberg, S. and B. Keysar. "Understanding Metaphorical Comparisons: Beyond Similarity." Psychological Review 97(1) (1990): 3-18.

Glucksberg, S., R. Kreuz and S.H. Rho. "Context can constrain lexical access: Implications for models of language comprehension." Journal of Experimental Psychology: Learning, Memory, and Cognition 12 (1986): 323-335.

Grice, H.P. "Logic and conversation." Speech Acts. Syntax and Semantics Vol. 3. Eds. P. Cole and J. Morgan, New York: Academic Press, 1975, 41-58.

Horton, W. S. and B. Keysar. "When do speakers take into account common ground?" Cognition 59 (1996): 91-117.

Jones, J.L.. "Early integration of context during lexical access of homonym meanings." Current Psychology: Research \& Review 10(3) (1991): 163-181.

Jurafsky, D. "A probabilistic model of lexical and syntactic access and disambiguation." Cognitive Science 20 (1996): 137-194.

Kemper, S. "Comprehension and interpretation of proverbs." Journal of Psycholinguistic Research 10 (1981): 179-183.

Keysar, B. "On the functional equivalence of literal and metaphorical interpretations in discourse." Journal of Memory and Language 28 (1989): 375-385.

Keysar, B. "The illusory transparency of intention: Linguistic perspective taking in text. Cognitive psychology 26 (1994): 165-208.

Keysar, B., D. J. Barr, J. A. Balin and T.S. Paek "Definite reference and mutual knowledge: Process models of common ground in comprehension." Memory and Language (in press).

Keysar, B., D. J. Barr, and W.S Horton. "The egocentric basis of language use: Insights from a processing approach." Current Directions in Psychological Sciences (in press).

Kotthoff, H. "Irony, citation, and other forms of staged intertextuality: Double or contrastive perspective in conversation." Perspectivity in discourse. Eds. C. Graumann, W. Kallmeyer (1998a) Amsterdam: Benjamins.

Kotthoff, H. "Responding to conversational irony." Paper presented at AILA (1998b). 
Inhoff, A.W., S. D. Lima and P.J. Carroll. "Contextual effects on metaphor comprehension in reading." Memory and Cognition 12 (1984): 558-567.

McGlone, M.S., S.Glucksberg and C. Cacciari. "Semantic productivity and idiom comprehension." Discourse Processes 17 (1994): 167-190.

Onifer, W., D.A. Swinney. "Accessing lexical ambiguities during sentence comprehension: Effects of frequency of meaning and contextual bias." Memory \& Cognition 9 (1981): 225-236.

Ortony, A., D.L. Schallert, R.E. Reynolds and S.J. Antos. "Interpreting metaphors and idioms: Some effects of context on comprehension." Journal of Verbal Learning and Verbal Behavior 17 (1978): 465-477.

Rayner, K., J.M. Pacht and S.A. Dutfy. "Etfects of prior encounter and global discourse bias on the processing of lexically ambiguous words: Evidence from eye fixations." Journal of Memory and Language 33 (1994): 527-544.

Récanati, F. "The alleged priority of literal meaning." Cognitive Science 19 (1995): 207-232.

Searle, J. Expression and Meaning. Cambridge, England: Cambridge University Press, 1979.

Shen, Y. "Metaphors and global conceptual structures." Poetics 25(1) (1997): 1-17.

Simon, H.A. "Rational choice and the structure of the environment." Psychologica Review 63 (1956): 129-138.

Simpson, B.G. "Meaning dominance and semantic context in the processing of lexical ambiguity." Journal of Verbal Learning and Verbal Behavior 20 (1981): 120-136.

Smith, N. and D. Wilson. "Introduction." Lingua 87 (1992): 1-10.

Sperber, D. and D. Wilson Relevance: Communication and Cognition. Oxford: Blackwell, $1986 / 1995$.

Swinney, D.A. "Lexical access during sentence comprehension: (Re)consideration of context effects." Journal of Verbal Learning and Verbal Behavior 18 (1979): 645-659.

Turner, N.E. and A. Katz. "Evidence tor the availability of conventional and of literal meaning during the comprehension of proverbs." Pragmatics and Cognition 5 (1997): 203-237.

Tverski, Amos and Daniel Kahneman. "Judgement under uncertainty: Heuristics and biases. Science 185 (1974): 1124-1131.

Zaidel, E. Hemispheric monitoring. In D. Ottoson (ed.), Duality and Unity of the Brain. Hampshire, Macmillan, 1987: 247-281. 